\title{
Inhibiting Effects of Rabeprazole Sulfide on the Corrosion of Mild Steel in Acidic Chloride Solution
}

\author{
M. K. Pavithra, T. V. Venkatesha, and M. K. Punith Kumar \\ Department of Chemistry, School of Chemical Sciences, Jnana Sahyadri Campus, Kuvempu University, Shankaraghatta, \\ Karnataka 577451, India
}

Correspondence should be addressed to T. V. Venkatesha; drtvvenkatesha@yahoo.co.uk

Received 18 February 2013; Revised 22 April 2013; Accepted 22 April 2013

Academic Editor: Sheng S. Zhang

Copyright (c) 2013 M. K. Pavithra et al. This is an open access article distributed under the Creative Commons Attribution License, which permits unrestricted use, distribution, and reproduction in any medium, provided the original work is properly cited.

\begin{abstract}
The corrosion inhibition effect of Rabeprazole sulfide (RS) on mild steel in $1 \mathrm{M}$ hydrochloric acid (HCl) was investigated using weight loss, potentiodynamic polarization, electrochemical impedance spectroscopy (EIS), and chronoamperometric measurements. Protection efficiency of RS increases with the concentration and decreases with the rise in temperature. Adsorption of RS on mild steel surface in $1 \mathrm{M} \mathrm{HCl}$ follows Langmuir adsorption isotherm. The kinetic and thermodynamic parameters governing the adsorption process were calculated and discussed. The polarization results suggest that RS performed as an excellent mixed-type inhibitor for mild steel corrosion in $1 \mathrm{M} \mathrm{HCl}$.
\end{abstract}

\section{Introduction}

Mild steel is widely used in many industries due to its excellent mechanical properties and low cost. However, it undergoes corrosion to a greater extent in acidic environment. Acids are employed in several industrial processes such as acid pickling, cleaning, acid descaling, and oil well acidizing. The use of $\mathrm{HCl}$ in these processes is more economical, efficient, and trouble-free, compared to other mineral acids [1]. In order to avoid the base metal attack, chemical inhibitors are often used for these processes to control the metal dissolution. The most well-known acid corrosion inhibitors are the heterocyclic compounds containing nitrogen, sulphur, and oxygen atoms [2-5].

Generally inhibitors act through the process of surface adsorption and its adsorption depends on the nature and surface charges on the metal, the type of aggressive media, the structure of inhibitor molecules, and its interaction with the metal surface [6]. Previously, large numbers of organic compounds have been investigated as corrosion inhibitors for mild steel in $\mathrm{HCl}$ media [7-11]. Even though these compounds show good anticorrosive action, they are toxic in nature. This led investigations to focus on the development of nontoxic corrosion inhibitors like drugs. A few investigations have been reported on the use of drugs such as cefazolin [1], Ampicillin [12], antifungal drugs [13], sulfa drugs [14], and rhodanine azosulpha drugs [15] as corrosion inhibitors. The inhibitory action of tramadol and tacrine on mild steel in $1 \mathrm{M}$ $\mathrm{HCl}$ has been reported by Prabhu et al. [16] and Nataraja et al. [17].

Rabeprazole sulfide is the commercial name of (2-[[4-(3Methoxypropoxy)-3-methylpyridine-2-yl]-methylthio]-1Hbenzimidazole). It is a metabolite of an antiulcer drug, Rabeprazole. We have investigated the corrosion inhibition effect of this compound on mild steel in $0.5 \mathrm{M} \mathrm{H}_{2} \mathrm{SO}_{4}$ media in a previous article [18]. However, according to literature study, there is no report found on corrosion inhibition studies of Rabeprazole sulfide in $\mathrm{HCl}$ medium. Hence the present work has been carried out to examine the potential of Rabeprazole sulfide to control corrosion of mild steel in $1 \mathrm{M} \mathrm{HCl}$ medium. The aim of this study is to explore the use of Rabeprazole sulfide as an acid corrosion inhibitor for mild steel surface in $\mathrm{HCl}$ solution using weight loss, potentiodynamic polarization, EIS, and the chronoamperometric techniques. Also the thermodynamic parameters for the adsorption process and activation parameters for the mild steel dissolution reactions are calculated and discussed. 


\section{Methods and Materials}

The experiments were performed with mild steel specimens having the composition $0.04 \% \mathrm{C}, 0.35 \% \mathrm{Mn}, 0.022 \% \mathrm{P}$, and $0.036 \% \mathrm{~S}$ and the remainder being $\mathrm{Fe}$, which were used for weight loss as well as electrochemical studies. The mild steel coupons of dimension $4 \mathrm{~cm} \times 2 \mathrm{~cm} \times 0.1 \mathrm{~cm}$ were used for weight loss measurements and those of $1 \mathrm{~cm}^{2}$ area (exposed) with a $5 \mathrm{~cm}$ long stem isolated with araldite resin were used for electrochemical experiments. Prior to each experiment, the mild steel samples were abraded with series of emery papers of grade number 220, 660, and 1200 followed by washing in double distilled water and acetone and then dried.

The aggressive solutions of $1 \mathrm{M} \mathrm{HCl}$ were prepared using AR grade chemicals and double distilled water. The test inhibitor RS was obtained from Ramdev Chemicals India Pvt. Ltd., Mumbai, and its structure is as shown in Figure 1. The desired concentrations of inhibitor solutions $(0.05,0.1,0.5$, and $1.0 \mathrm{mM}$ ) were prepared by dissolving specified amount of RS in $1 \mathrm{M} \mathrm{HCl}$ solution.

The weight loss of precleaned and dried mild steel specimens were determined by weighing the metal samples before and after immersing in $100 \mathrm{~cm}^{3}$ of $1 \mathrm{M} \mathrm{HCl}$ in the absence and presence of various concentration of RS at 303, 313,323 , and $333 \mathrm{~K}$. The experiments were performed in triplicate and the mean value is reported. All experiments were carried out in aerated and static conditions.

The electrochemical measurements were conducted in a conventional glass cell using $\mathrm{CHI}$ 660C electrochemical analyzer (USA make). A mild steel specimen ( $1 \mathrm{~cm}^{2}$ area), a platinum electrode, and a saturated calomel electrode were used as working, auxiliary, and reference electrodes. In case of polarization and electrochemical impedance spectroscopic measurements (EIS) prior to each measurement, a stabilization period of $30 \mathrm{~min}$ was allowed to establish a steady state open circuit potential (OCP). Each experiment was carried out in triplicate and the average values of corrosion parameters are reported.

The potentiodynamic polarization measurements were carried out over a potential automatically from $+200 \mathrm{mV}$ to $-200 \mathrm{mV}$ at OCP with a scan rate of $0.5 \mathrm{mV} \mathrm{s}^{-1}$. All the potentials reported were with reference to SCE. The corrosion kinetic parameters such as corrosion potential $\left(E_{\text {corr }}\right)$, corrosion current density $\left(I_{\text {corr }}\right)$, and anodic $\left(\beta_{a}\right)$ /cathodic $\left(\beta_{c}\right)$ Tafel slopes were generated from the software installed in the instrument. The EIS measurements were carried at OCP in the frequency range $1 \mathrm{mHz}$ to $100 \mathrm{kHz}$ with $5 \mathrm{mV}$ sine wave as the excitation signal. Impedance data were analyzed using ZSimp-Win 3.21 software. The chronoamperometric experiments were performed by polarizing the working electrode anodically at $-0.41 \mathrm{~V}$ (SCE) for $600 \mathrm{~s}$.

\section{Results and Discussion}

3.1. Weight Loss Measurements. Weight loss method is used for monitoring corrosion rate because of its simple application and reliability. Weight loss of mild steel surface in $1 \mathrm{M}$ $\mathrm{HCl}$ was determined at $301-333 \mathrm{~K}$ in the absence and presence

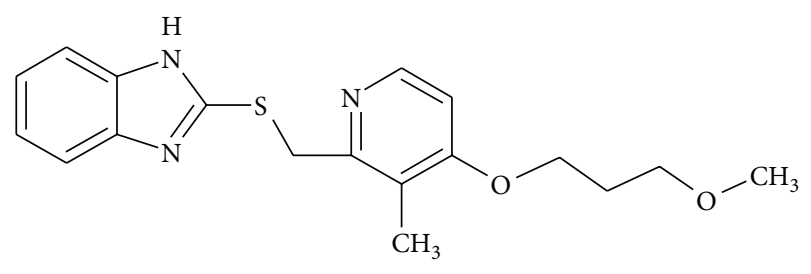

FIgURE 1: The chemical structure of RS.

of different concentration of RS. The obtained corrosion parameters are tabulated in Table 1 . The corrosion rate $\left(v_{\text {corr }}\right)$ of mild steel was determined using the relation

$$
v_{\text {corr }}=\frac{\Delta m}{S t}
$$

where $\Delta m$ is the corrosion weight loss of mild steel ( $\mathrm{g}), S$ is the surface area of mild steel specimen $\left(\mathrm{cm}^{2}\right)$, and $t$ is the time of exposure.

The percentage inhibition efficiency $\eta_{w}(\%)$ was calculated using the relationship;

$$
\eta_{w}(\%)=\frac{v_{\text {corr }}^{o}-v_{\text {corr }}}{v_{\text {corr }}^{o}} \times 100,
$$

where $v_{\text {corr }}^{o}$ and $v_{\text {corr }}$ are the corrosion rates of mild steel in the absence and presence of RS, respectively.

It can be seen from Table 1 that the $v_{\text {corr }}$ decreases and the inhibition efficiency increases with the concentration of the inhibitor. This is due to an increase in the amount of adsorption and coverage of inhibitor on mild steel surface [1]. It is also apparent from the table that the $v_{\text {corr }}$ increases and inhibition efficiency decreases with increasing the temperature. This suggests the physisorption of the inhibitor on metal surface [19]. The increase in $v_{\text {corr }}$ is more pronounced at lower concentration of RS (0.05 and $0.1 \mathrm{mM})$. However, at higher concentration $(0.5$ and $1.0 \mathrm{mM})$ the temperature has very little effect on the $v_{\text {corr }}$ which can be attributed to slight change in the nature of mode of adsorption, where the chemisorption accompanied by physisorption may occur.

\subsubsection{Thermodynamic Parameters of the Adsorption Isotherm.} Basic information on the interaction between the inhibitor and the mild steel surface can be provided by the adsorption isotherm. Hence in order to know the mode of adsorption of RS on mild steel surface in $1 \mathrm{M} \mathrm{HCl}$ at $303-333 \mathrm{~K}$, attempts were made to fit experimental data with several adsorption isotherms like Langmuir, Temkin, Bockris-Swinkels, Freundlich, and Flory-Huggins isotherms. The best fit was obtained with Langmuir isotherm given by the equation [20]

$$
\frac{C}{\theta}=\frac{1}{K_{\mathrm{ads}}}+C,
$$

where $C$ is the molar concentration of inhibitor, $K_{\text {ads }}$ is the equilibrium constant of adsorption process, and $\theta$ is the degree of surface coverage defined as $\eta_{w}(\%) / 100$. The plots of $C / \theta$ against $C$ for the inhibitor were straight lines and are given in Figure 2. It is found that all the regression coefficients 
TABLE 1: Effect of temperature on the corrosion rate of mild steel in $1 \mathrm{M} \mathrm{HCl}$ at different concentrations of RS.

\begin{tabular}{|c|c|c|c|c|c|c|c|c|}
\hline \multirow{3}{*}{$\mathrm{C}(\mathrm{mM})$} & \multicolumn{8}{|c|}{ Temperature } \\
\hline & \multicolumn{2}{|c|}{$303 \mathrm{~K}$} & \multicolumn{2}{|c|}{$313 \mathrm{~K}$} & \multicolumn{2}{|c|}{$323 \mathrm{~K}$} & \multicolumn{2}{|c|}{$333 \mathrm{~K}$} \\
\hline & $\begin{array}{c}v_{\text {corr }} \\
\left(\mathrm{mg} \mathrm{cm}^{-2} \mathrm{~h}^{-1}\right)\end{array}$ & $\eta_{w}(\%)$ & $\begin{array}{c}v_{\text {corr }} \\
\left(\mathrm{mg} \mathrm{cm}^{-2} \mathrm{~h}^{-1}\right)\end{array}$ & $\eta_{w}(\%)$ & $\begin{array}{c}v_{\text {corr }} \\
\left(\mathrm{mg} \mathrm{cm}^{-2} \mathrm{~h}^{-1}\right)\end{array}$ & $\eta_{w}(\%)$ & $\begin{array}{c}v_{\text {corr }} \\
\left(\mathrm{mg} \mathrm{cm}^{-2} \mathrm{~h}^{-1}\right)\end{array}$ & $\eta_{w}(\%)$ \\
\hline Blank & 0.85 & & 2.48 & & 8.08 & & 16.95 & \\
\hline 0.05 & 0.33 & 60.62 & 1.44 & 42.12 & 6.11 & 24.37 & 14.73 & 13.08 \\
\hline 0.1 & 0.27 & 68.35 & 1.21 & 51.32 & 4.87 & 39.67 & 13.32 & 21.41 \\
\hline 0.5 & 0.14 & 83.47 & 0.43 & 82.48 & 1.53 & 81.03 & 3.37 & 80.12 \\
\hline 1.0 & 0.07 & 91.42 & 0.23 & 90.76 & 0.82 & 89.83 & 1.86 & 89.02 \\
\hline
\end{tabular}

TABLE 2: Thermodynamic parameters for the adsorption of RS in $1 \mathrm{M} \mathrm{HCl}$ on the mild steel at different temperatures.

\begin{tabular}{lcccc}
\hline Temperature $(\mathrm{K})$ & Slope & $R^{2}$ & $K_{\mathrm{ads}}\left(\mathrm{M}^{-1}\right)$ & $\Delta G_{\mathrm{ads}}\left(\mathrm{kJ} \mathrm{mol}^{-1}\right)$ \\
\hline $303 \mathrm{~K}$ & 1.065 & 0.998 & 25000 & -35.63 \\
$313 \mathrm{~K}$ & 1.025 & 0.999 & 12195 & -34.94 \\
$323 \mathrm{~K}$ & 0.953 & 0.999 & 6536 & -34.38 \\
$333 \mathrm{~K}$ & 0.764 & 0.981 & 3058 & -33.33 \\
\hline
\end{tabular}
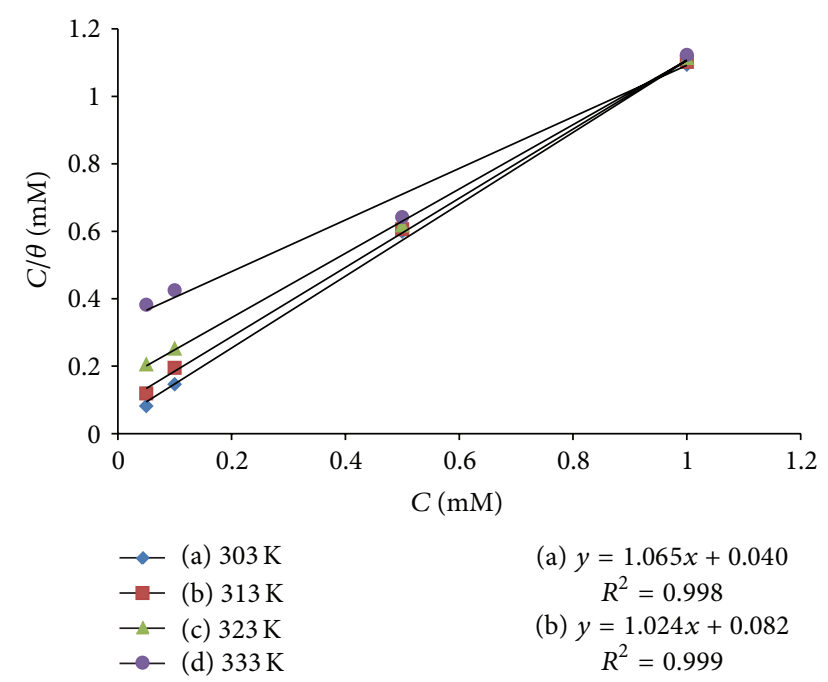

$$
\begin{gathered}
\text { (a) } y=1.065 x+0.040 \\
R^{2}=0.998 \\
\text { (b) } y=1.024 x+0.082 \\
R^{2}=0.999 \\
\text { (c) } y=0.953 x+0.153 \\
R^{2}=0.999 \\
\text { (d) } y=0.764 x+0.327 \\
R^{2}=0.981
\end{gathered}
$$

FIGURE 2: Langmuir adsorption isotherm for adsorption of RS on the mild steel surface in $1 \mathrm{M} \mathrm{HCl}$.

are very close to one, which indicates that the adsorption of RS on the mild steel surface in $1 \mathrm{M} \mathrm{HCl}$ follows Langmuir adsorption isotherm.

The $K_{\mathrm{ads}}$ can be calculated from the intercepts of the straight lines on the $C / \theta$ axis and it is related to the standard free energy of adsorption $\left(\Delta G_{\mathrm{ads}}^{o}\right)$ by the relation [21]

$$
K_{\mathrm{ads}}=\frac{1}{55.5} \exp \left(\frac{-\Delta G_{\mathrm{ads}}^{o}}{R T}\right)
$$

The obtained thermodynamic parameters are given in Table 2. The negative values of $\Delta G_{\text {ads }}^{o}$ indicate the spontaneous adsorption of RS on mild steel surface [22]. Also the high values of $K_{\mathrm{ads}}$ suggest the strong adsorption ability of RS on mild steel surface.

It is generally accepted that the values of $\Delta G_{\text {ads }}^{o}$ up to $-20 \mathrm{~kJ} \mathrm{~mol}^{-1}$ are consistent with physisorption and the values around $-40 \mathrm{~kJ} \mathrm{~mol}^{-1}$ or smaller are associated with chemisorption resulting from the sharing or transfer of electrons from organic molecule to the metal surface to form a coordinate bond [23]. However, the calculated $\Delta G_{\text {ads }}^{o}$ values are between $-20 \mathrm{~kJ} \mathrm{~mol}^{-1}$ and $-40 \mathrm{~kJ} \mathrm{~mol}^{-1}$. This signifies that the adsorption of RS on mild steel in $1 \mathrm{M} \mathrm{HCl}$ involves comprehensive adsorption where physisorption accompanied by chemisorption will take place.

Further the dependence of $\Delta G_{\text {ads }}^{o}$ on temperature can be explained by two cases as follows [24]:

(a) $\Delta G_{\text {ads }}^{o}$ may increase (become less negative) with the increase in temperature, which indicates the occurrence of exothermic process;

(b) $\Delta G_{\text {ads }}^{o}$ may decrease (become more negative) with increasing the temperature, indicating the occurrence of endothermic process.

It is clear from Table 2 that with the increase in the temperature, $\Delta G_{\mathrm{ads}}^{o}$ also increases and it specifies the corrosion inhibition of mild steel by RS is an exothermic process. Here the adsorption of RS on metal surface becomes unfavorable with increasing the reaction temperature due to the desorption of inhibitor from the mild steel surface [25]. The enthalpy of adsorption $\left(\Delta H_{\mathrm{ads}}^{o}\right)$ and entropy of adsorption can be evaluated by the integrated version of the Van't Hoff equation expressed as follows [26]:

$$
\ln K_{\mathrm{ads}}=\frac{-\Delta H_{\mathrm{ads}}^{o}}{R T}+\frac{\Delta S_{\mathrm{ads}}^{o}}{R}+\ln \frac{1}{55.5} .
$$

The variation of $\ln K_{\text {ads }}$ versus $1 / T$ gives a straight line (Figure 3) with the slope of $\left(-\Delta H_{\mathrm{ads}}^{o} / R\right)$ and intercept of $\left(\Delta S_{\text {ads }}^{o} / R+\ln 1 / 55.5\right)$. The calculated values of $\Delta H_{\text {ads }}^{o}$ and $-\Delta S_{\text {ads }}^{o}$ are $-58.76 \mathrm{~kJ} \mathrm{~mol}^{-1}$ and $76.103 \mathrm{~J} \mathrm{~mol}^{-1} \mathrm{~K}^{-1}$, respectively. 


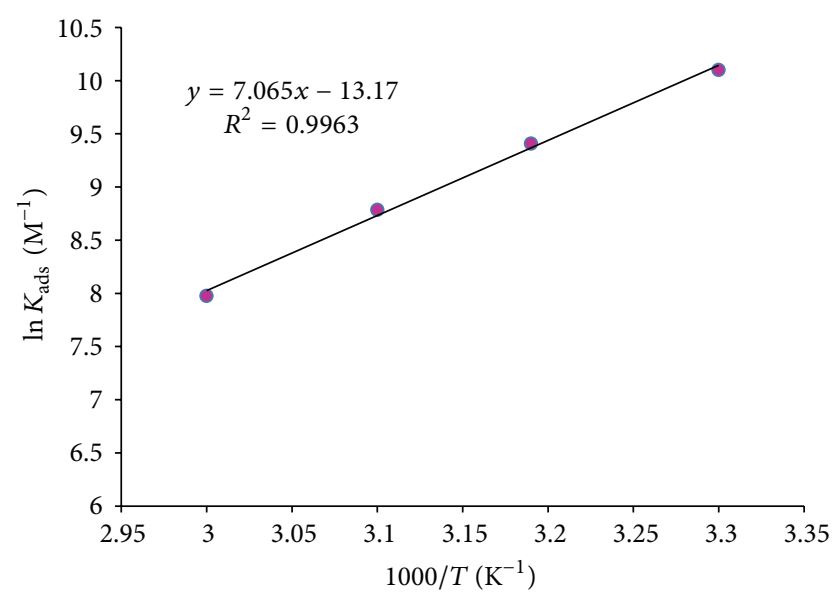

FIgURE 3: The relationship between $\ln K_{\text {ads }}$ and $1 / T$.

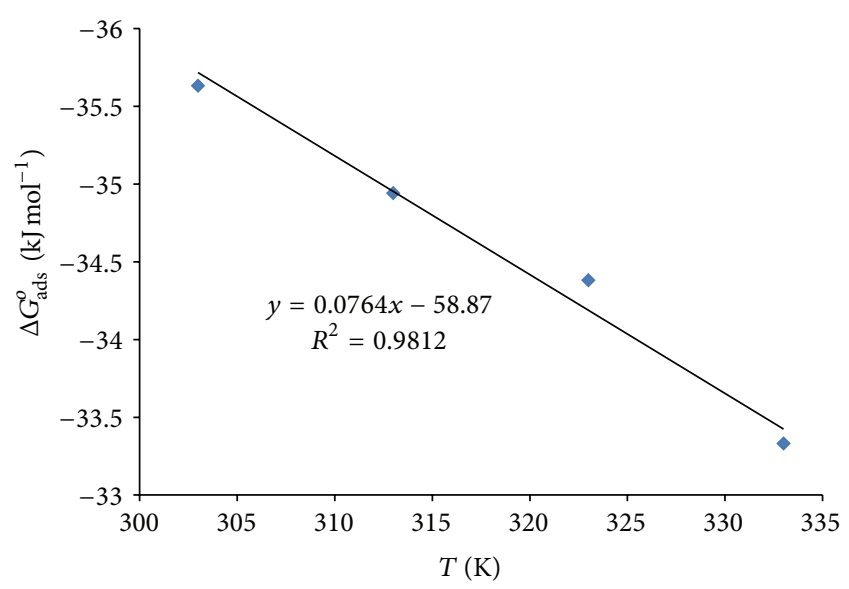

FIGURE 4: The relationship $\Delta G_{\mathrm{ads}}^{o}$ of RS and temperature $(T)$.

On the other hand, the enthalpy and entropy for the adsorption of RS on mild steel were also calculated using the thermodynamic equation [27]

$$
\Delta G_{\mathrm{ads}}^{o}=\Delta H_{\mathrm{ads}}^{o}-T \Delta S_{\mathrm{ads}}^{o} .
$$

A plot of $\Delta G_{\text {ads }}^{o}$ against $T$ was linear (Figure 4) with the slope equal to $-\Delta S_{\mathrm{ads}}^{o}$ and intercept of $\Delta H_{\mathrm{ads}}^{o}$. The obtained values of $\Delta H_{\mathrm{ads}}^{o}$ and $-\Delta S_{\mathrm{ads}}^{o}$ are $-58.87 \mathrm{~kJ} \mathrm{~mol}^{-1}$ and $76 \mathrm{~J} \mathrm{~mol}^{-1} \mathrm{~K}^{-1}$, respectively.

The negative values of $\Delta H_{\text {ads }}^{o}$ reflect the exothermic behavior of the adsorption of inhibitor on mild steel. Generally, an exothermic adsorption process signifies either physisorption or chemisorption while endothermic process is attributable to chemisorption [28]. In an exothermic process, both physisorption and chemisorption can be distinguished by considering the absolute value of $\Delta H_{\mathrm{ads}}^{o}$. For physisorption process, $\Delta H_{\mathrm{ads}}^{o}$ is lower, that is $40 \mathrm{~kJ} \mathrm{~mol}^{-1}$, while that for chemisorption approaches $100 \mathrm{~kJ} \mathrm{~mol}^{-1}$ [29]. In the present case $\Delta H_{\text {ads }}^{o}$ is $58.87 \mathrm{~kJ} \mathrm{~mol}^{-1}$, which is an intermediate case clearly specifies the existence of both physical and chemical adsorption. Thus $\Delta G_{\text {ads }}^{o}$ and $\Delta H_{\text {ads }}^{o}$ values complement
TABLE 3: Activation parameters of dissolution reaction of mild steel in $1 \mathrm{M} \mathrm{HCl}$ with $\mathrm{RS}$ at different concentrations.

\begin{tabular}{lcccc}
\hline$C(\mathrm{mM})$ & $\begin{array}{c}A \\
\left(\mathrm{~g} \mathrm{~cm}^{-2} \mathrm{~h}^{-1}\right)\end{array}$ & $\begin{array}{c}E_{a}^{*} \\
\left(\mathrm{~kJ} \mathrm{~mol}^{-1}\right)\end{array}$ & $\begin{array}{c}\Delta H^{*} \\
\left(\mathrm{~kJ} \mathrm{~mol}^{-1}\right)\end{array}$ & $\begin{array}{c}\Delta S^{*} \\
\left(\mathrm{~J} \mathrm{~mol}^{-1} \mathrm{~K}^{-1}\right)\end{array}$ \\
\hline Blank & $4.27 \times 10^{11}$ & 85.22 & 82.55 & -31.34 \\
0.05 & $1.338 \times 10^{15}$ & 107.75 & 105.09 & 35.92 \\
0.1 & $2.512 \times 10^{15}$ & 109.83 & 107.17 & 40.90 \\
0.5 & $2.615 \times 10^{15}$ & 112.74 & 109.99 & 41.15 \\
1.0 & $2.695 \times 10^{15}$ & 114.48 & 111.82 & 41.49 \\
\hline
\end{tabular}

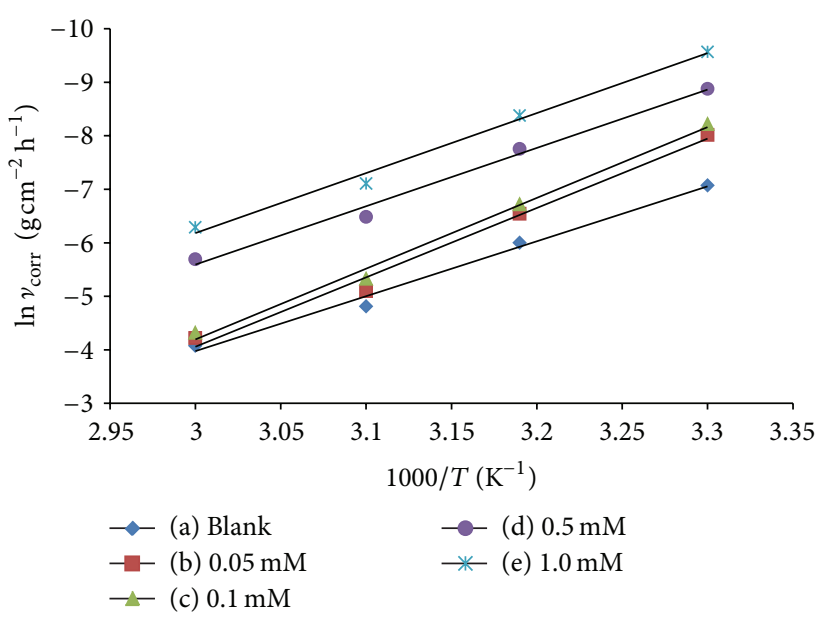

FIGURE 5: Arrhenius plot for mild steel in $1 \mathrm{M} \mathrm{HCl}$ solution with RS at different concentrations.

each other. As expected the values of $\Delta S_{\mathrm{ads}}^{o}$ are negative, because the exothermic adsorption process is associated with the decrease of entropy. Before adsorption, the inhibitor molecules move freely in bulk solution, and as the adsorption progresses, the adsorption of inhibitor molecules onto the mild steel surface becomes more orderly, resulting in a decrease in entropy [29]. Moreover, the values of $\Delta H_{\mathrm{ads}}^{o}$ and $-\Delta S_{\text {ads }}^{o}$ obtained by the two methods are in good agreement.

3.1.2. Effect of Temperature. To assess the effect of temperature on corrosion and corrosion inhibition process, weight loss experiments were carried out for mild steel in $1 \mathrm{M} \mathrm{HCl}$ at $303,313,323$, and $333 \mathrm{~K}$ in the absence and presence of different concentrations of RS. Usually corrosion reactions are regarded as Arrhenius processes and the $v_{\text {corr }}$ can be expressed by the relation

$$
\ln v_{\text {corr }}=\ln A-\frac{E_{a}^{*}}{R T},
$$

where $v_{\text {corr }}$ is the corrosion rate, $E_{a}^{*}$ is the apparent activation energy, $R$ is the Universal gas constant $\left(8.314 \mathrm{~J} \mathrm{~K}^{-1} \mathrm{~mol}^{-1}\right), T$ is the absolute temperature, and $A$ is the frequency factor. The Arrhenius plot is shown in Figure 5 and the plot of $\ln v_{\text {corr }}$ against $1 / T$ gives straight lines with slope $-E_{a}^{*} / R$ and the intercept of $\ln A$. The obtained values of $E_{a}^{*}$ and $A$ are presented in Table 3. 


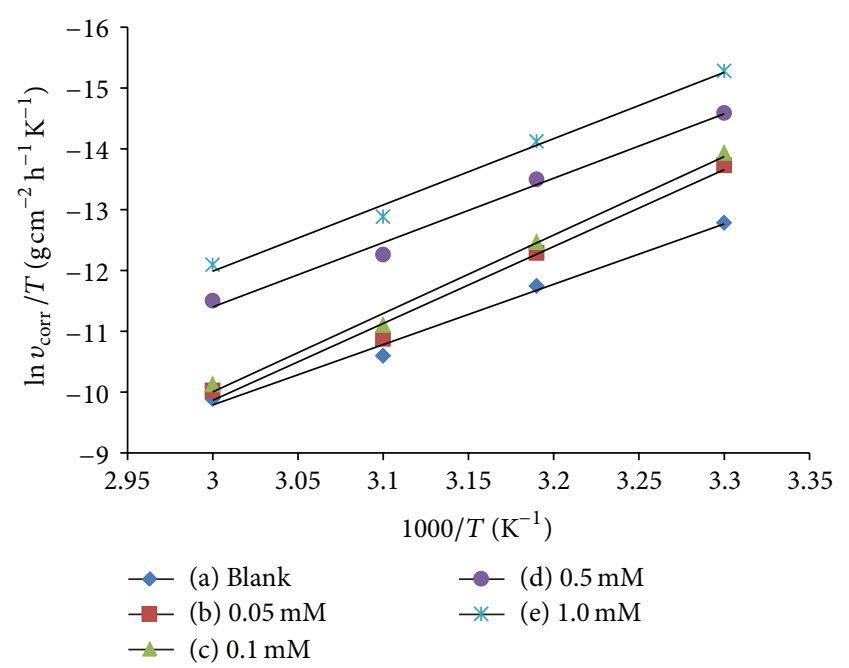

Figure 6: Transition state plot for mild steel in $1 \mathrm{M} \mathrm{HCl}$ solution with RS at different concentrations.

The change in enthalpy $\left(\Delta H^{*}\right)$ and entropy $\left(\Delta S^{*}\right)$ of activation was calculated by the transition state equation given below:

$$
\ln \frac{v_{\text {corr }}}{T}=\left[\ln \frac{R}{N h}+\frac{\Delta S^{*}}{R}\right]-\frac{\Delta H^{*}}{R T},
$$

where $h$ is the Planck's constant and $N$ is the Avogadro's number. The plot of $\ln v_{\text {corr }} / T$ against $1 / T$ for mild steel corrosion in $1 \mathrm{M} \mathrm{HCl}$ without and with RS is shown in Figure 6. Straight lines were obtained with slope of $-\Delta H^{*} / R$ and intercept of $\left[\ln R / N h+\Delta S^{*} / R\right)$ from which the values of $\Delta H^{*}$ and $\Delta S^{*}$ were calculated and tabulated in Table 3.

It is evident from the table that both the $E_{a}^{*}$ and frequency factor values with increasing concentration of RS and the $E_{a}^{*}$ in the inhibited solution are higher than those in the uninhibited solution. The higher value of $E_{a}^{*}$ in presence of RS can be attributed to an increase in the thickness of double layer which increases the $E_{a}^{*}$ for corrosion process [17]. The $E_{a}^{*}$ for the corrosion process, both in the absence and presence of inhibitor, is greater than $20 \mathrm{~kJ} \mathrm{~mol}^{-1}$ and hence the entire process is controlled by surface reaction [30]. These results disclose that the corrosion reaction of mild steel is inhibited by RS.

Based on the temperature effects, the relationships between the temperature dependence of $\eta_{w}(\%)$ of an inhibitor and the $E_{a}^{*}$ can be classified into three groups [31]:

(1) $\eta_{w}(\%)$ decreases with the increase in temperature, $E_{a}^{*}$ (inhibited solution) $>E_{a}^{*}$ (uninhibited solution);

(2) $\eta_{w}(\%)$ increases with the increase in temperature, $E_{a}^{*}$ (inhibited solution) $<E_{a}^{*}$ (uninhibited solution);

(3) $\eta_{w}(\%)$ does not change with temperature, $E_{a}^{*}$ (inhibited solution $)=E_{a}^{*}$ (uninhibited solution).

In the present case, $\eta_{w}(\%)$ decreases with the increase in temperature and hence $E_{a}^{*}$ (inhibited solution) $>E_{a}^{*}$

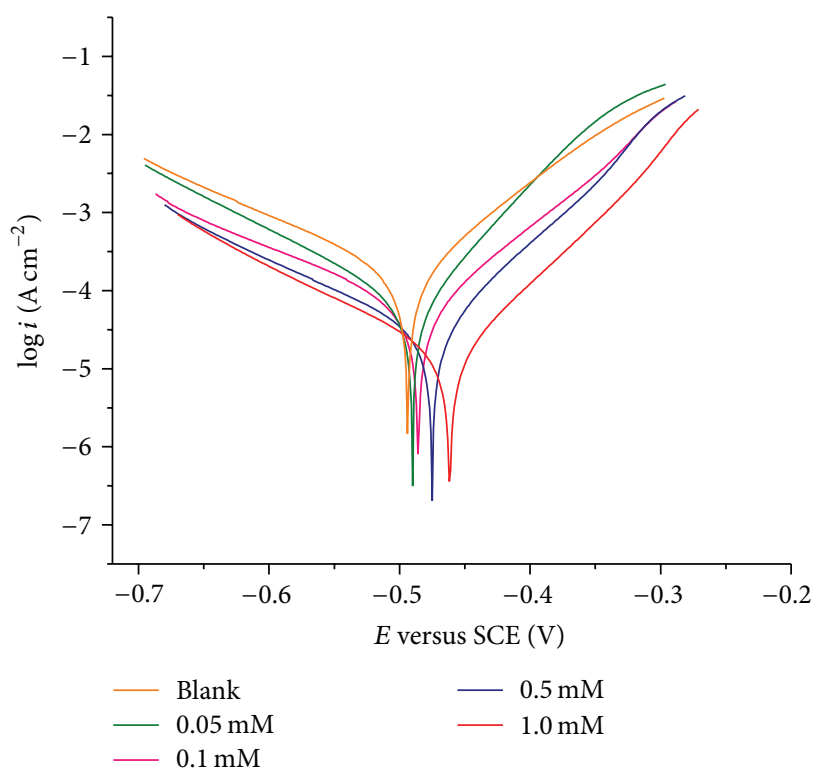

Figure 7: Polarisation curves for mild steel in $1 \mathrm{M} \mathrm{HCl}$ in the presence of various concentrations of RS.

(uninhibited solution). This suggests the physisorption. But in some cases, the chemical adsorption is accepted as the most probable type of adsorption, although inhibition efficiency decreases with rising the temperature and $E_{a}^{*}$ is higher than that in the absence of inhibitor [32]. The activation parameters $\left(\Delta H^{*}\right.$ and $\left.\Delta S^{*}\right)$ of mild steel dissolution reaction in $1 \mathrm{M} \mathrm{HCl}$ in the presence of RS are higher than those in the absence of inhibitor. The positive values of enthalpy reflect the endothermic nature of mild steel dissolution process. The average difference value of the $E_{a}^{*}-\Delta H^{*}$ is $2.66 \mathrm{~kJ} \mathrm{~mol}^{-1}$, which is approximately equal to the average value of $R T$ $\left(2.685 \mathrm{~kJ} \mathrm{~mol}^{-1}\right)$ at $323 \mathrm{~K}$. This infers that the corrosion process is an unimolecular reaction which is characterized by the following equation [25]:

$$
E_{a}^{*}-\Delta H^{*}=R T
$$

The positive values of $\Delta S^{*}$ in the presence of inhibitor imply that the rate determining step for the activated complex is dissociation step rather than an association, meaning that the adsorption process is accompanied by an increase in entropy, which is the driving force for the adsorption of inhibitor molecules on the mild steel surface [33].

\subsection{Electrochemical Measurements}

3.2.1. Polarisation Measurements. The influence of RS on the cathodic and anodic potentiodynamic polarization curves of mild steel in $1 \mathrm{M} \mathrm{HCl}$ at $303 \mathrm{~K}$ is shown in Figure 7. The corrosion kinetic parameters such as corrosion potential $\left(E_{\text {corr }}\right)$, corrosion current density $\left(I_{\text {corr }}\right)$, and anodic $\left(\beta_{a}\right) /$ cathodic $\left(\beta_{c}\right)$ Tafel slopes are presented in Table 4 . The percentage 
TABLE 4: Polarization parameters of mild steel in $1 \mathrm{M} \mathrm{HCl}$ containing different concentrations of RS.

\begin{tabular}{lccccc}
\hline $\begin{array}{l}C \\
(\mathrm{mM})\end{array}$ & $\begin{array}{c}-E_{\text {corr }} \\
(\mathrm{mV})\end{array}$ & $\begin{array}{c}\beta_{c} \\
\left(\mathrm{mV} \mathrm{dec}^{-1}\right)\end{array}$ & $\begin{array}{c}\beta_{a} \\
\left(\mathrm{mV} \mathrm{dec}^{-1}\right)\end{array}$ & $\begin{array}{c}I_{\text {corr }} \\
\left(\mu \mathrm{A} \mathrm{cm}^{-2}\right)\end{array}$ & $\begin{array}{c}\eta_{T} \\
(\%)\end{array}$ \\
\hline Blank & 494 & 140.50 & 77.51 & 165.6 & \\
0.05 & 490 & 116.30 & 56.48 & 65.48 & 60.51 \\
0.1 & 486 & 149.16 & 76.38 & 59.92 & 63.81 \\
0.5 & 475 & 131.06 & 67.40 & 32.58 & 80.33 \\
1.0 & 462 & 126.37 & 63.44 & 16.54 & 90.01 \\
\hline
\end{tabular}

inhibition efficiency $\eta_{T}(\%)$ was computed from $\left(I_{\text {corr }}\right)$ values using the following expression:

$$
\eta_{T}(\%)=\frac{I_{\text {corr }}^{o}-I_{\text {corr }}}{I_{\text {corr }}^{o}} \times 100,
$$

where $I_{\text {corr }}^{o}$ and $I_{\text {corr }}$ are the corrosion current densities without and with RS, respectively.

As it can be seen from the polarization result, the $I_{\text {corr }}^{o}$ decreases and $\eta_{T}(\%)$ increases with increasing inhibitor concentration. This confirms the corrosion inhibition action of RS. Moreover the cathodic and anodic Tafel slope values changed with the inhibitor concentration, indicating that RS controlled both the cathodic hydrogen evolution and anodic mild steel dissolution reactions. It can be seen that the addition of RS to $1 \mathrm{M} \mathrm{HCl}$ shifted the $E_{\text {corr }}$ values to more positive direction and also the anodic and cathodic branches of polarization curves of pure acid solution towards lower current densities. An inhibitor can be classified as an anodic or cathodic type when the change in $E_{\text {corr }}$ value is larger than $85 \mathrm{mV}$ [34]. But the largest displacement exhibited by RS was $32 \mathrm{mV}$ versus SCE and hence it acts as a mixedtype inhibitor. So it can be concluded that RS behaves as a mixed-type inhibitor by inhibiting both anodic and cathodic reactions.

3.2.2. Electrochemical Impedance Spectroscopic Measurements. EIS has been widely used in investigating corrosion inhibition process since it provides more information on both the resistive and capacitive behavior at metal/solution interface. The corrosion behavior of mild steel in $1 \mathrm{M} \mathrm{HCl}$ with and without RS at $303 \mathrm{~K}$ was investigated using this technique and the obtained impedance data represented as Nyquist and Bode plots in Figures 8 and 9, respectively. Both these figures endorse that the impedance response of mild steel increases by the addition of RS.

The impedance spectra (Figure 8) exhibit single semicircle which can be attributed to the charge transfer that takes place at electrode/solution interface and this process controls the corrosion of mild steel. The presence of RS does not change the mechanism of mild steel dissolution [35]. Due to frequency dispersion, the Nyquist plots are not perfect semicircle, which is attributed to surface inhomogeneity and roughness [36].

The EIS results are simulated using the electrochemical equivalent circuit shown by the inset of Figure 8 . The

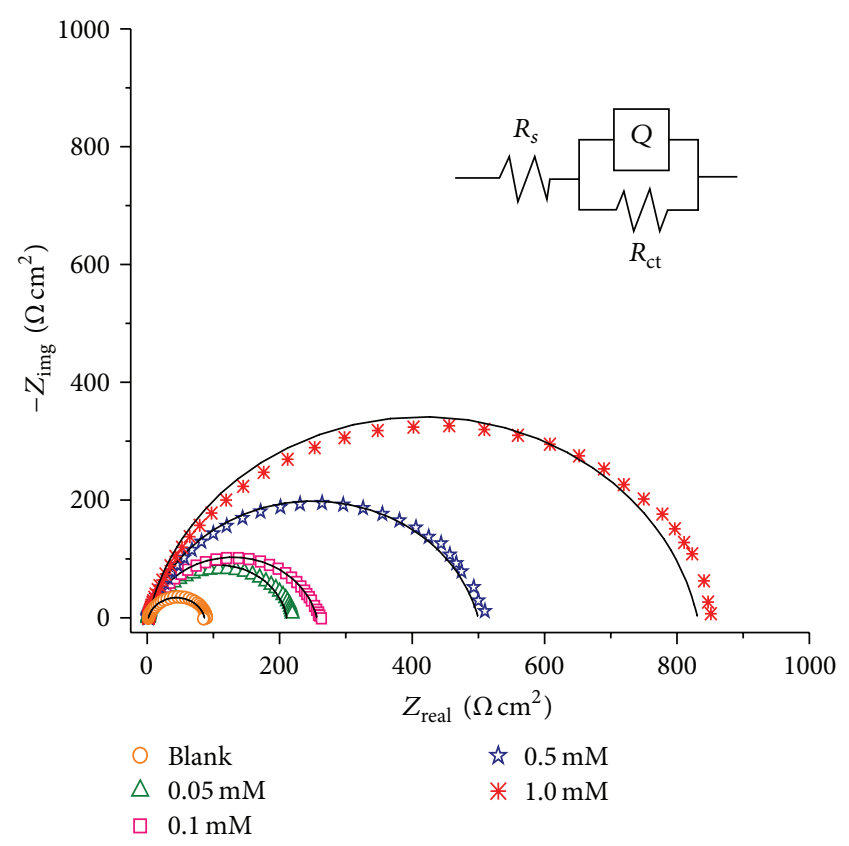

FIGURE 8: Nyquist plot (solid line shows fitted results) of mild steel in $1 \mathrm{M} \mathrm{HCl}$ solution without and with different concentrations of RS.

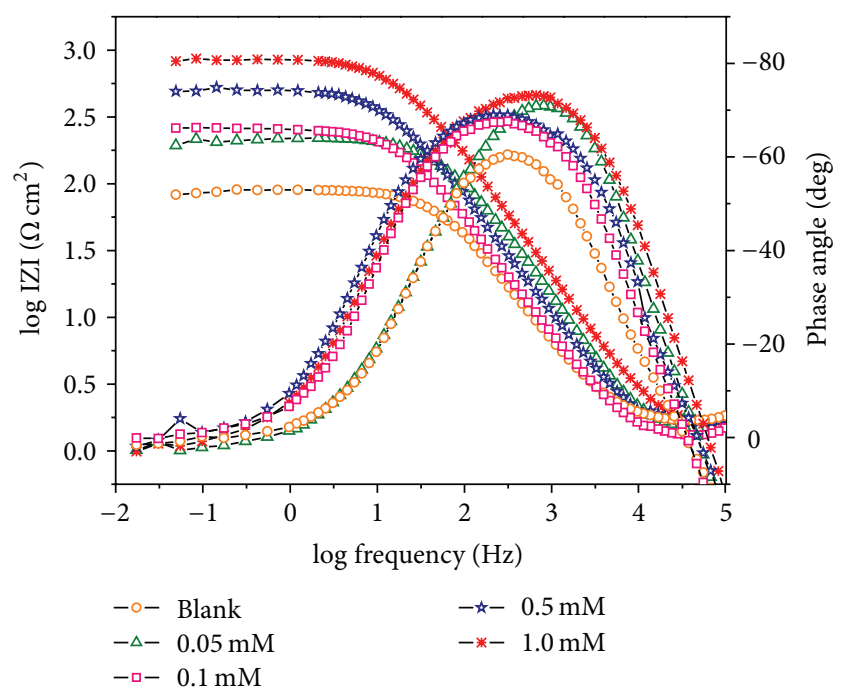

FIGURE 9: Bode plots of mild steel in $1 \mathrm{M} \mathrm{HCl}$ solution without and with different concentrations of RS.

equivalent circuit composed of the solution resistance $\left(R_{s}\right)$, the charge transfer resistance $\left(R_{\mathrm{ct}}\right)$, and the constant phase element (CPE) which describes the interfacial double layer. The impedance of CPE can be represented as follows:

$$
Z_{\mathrm{CPE}}=Q^{-1}(j \omega)^{-n},
$$

where $Q$ is the $\mathrm{CPE}$ constant, $\omega$ is the angular frequency, $j^{2}=-1$ is the imaginary number, and $n$ represents phase 
TABLE 5: Electrochemical impedance parameters of mild steel in $1 \mathrm{M}$ $\mathrm{HCl}$ containing different concentrations of RS.

\begin{tabular}{lccccc}
\hline $\begin{array}{l}C \\
(\mathrm{mM})\end{array}$ & $\begin{array}{c}R_{\mathrm{ct}} \\
\left(\Omega \mathrm{cm}^{2}\right)\end{array}$ & $\begin{array}{c}Q \\
\left(\mu \Omega^{-1} \mathrm{~S}^{n} \mathrm{~cm}^{-2}\right)\end{array}$ & $n$ & $\begin{array}{c}C_{\mathrm{dl}} \\
\left(\mu \mathrm{F} \mathrm{cm}^{-2}\right)\end{array}$ & $\eta_{z}(\%)$ \\
\hline Blank & 85 & 115.20 & 0.863 & 55.27 & \\
0.05 & 209.3 & 92.14 & 0.870 & 50.97 & 59.33 \\
0.1 & 254.8 & 89.09 & 0.864 & 49.12 & 66.67 \\
0.5 & 498.2 & 73.24 & 0.856 & 41.98 & 82.93 \\
1.0 & 829.6 & 31.62 & 0.877 & 18.96 & 89.76 \\
\hline
\end{tabular}

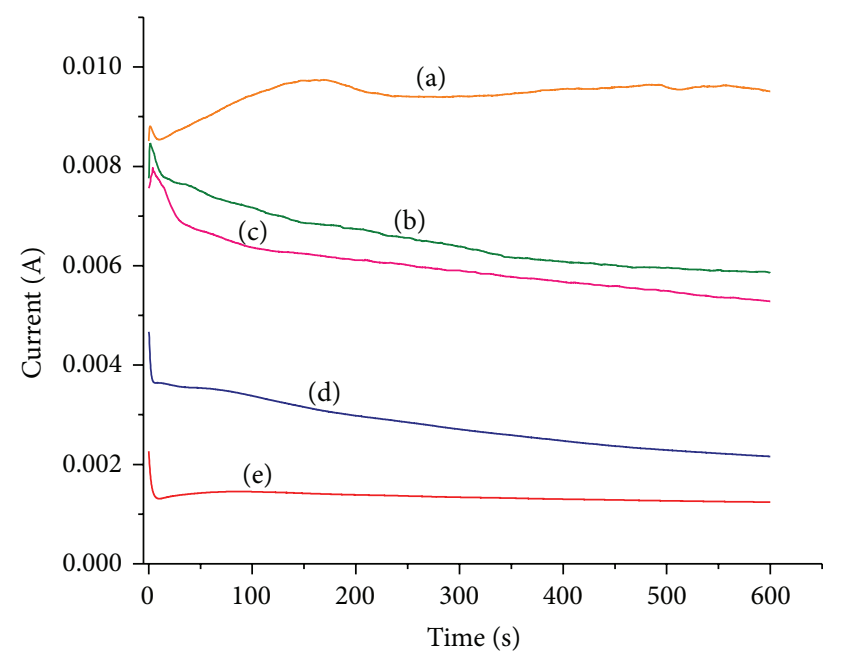

$\begin{array}{ll}\text { - (a) Blank } & - \text { (d) } 0.5 \mathrm{mM} \\ \text { (b) } 0.05 \mathrm{mM} & \text { (e) } 1.0 \mathrm{mM} \\ \text { (c) } 0.1 \mathrm{mM} & \end{array}$

Figure 10: Chronoamperometric curves of mild steel in $1 \mathrm{M} \mathrm{HCl}$ without and with different concentrations of RS.

shift which gives details about the degree of surface inhomogeneity resulting from surface roughness, inhibitor adsorption, porous layer formation, and so forth [37].

Further the double layer capacitance $\left(C_{\mathrm{dl}}\right)$ can be calculated by the relation

$$
\left(C_{\mathrm{dl}}\right)=\left(Q R_{\mathrm{ct}}^{1-n}\right)^{1 / n} .
$$

The values of impedance parameters derived from Nyquist plots for corrosion of mild steel in $1 \mathrm{M} \mathrm{HCl}$ in the absence and presence of RS are tabulated in Table 5. The inhibition efficiency $\eta_{Z}(\%)$ was evaluated from charge transfer resistance $\left(R_{\mathrm{ct}}\right)$ values using the following equation:

$$
\eta_{Z}(\%)=\frac{R_{\mathrm{ct}}-R_{\mathrm{ct}}^{o}}{R_{\mathrm{ct}}} \times 100
$$

where $R_{\mathrm{ct}}^{o}$ and $R_{\mathrm{ct}}$ are the charge transfer resistances without and with RS, respectively.

It is clear from Table 5 that by increasing the concentration of inhibitor, $Q$ and $C_{\mathrm{dl}}$ decrease and $R_{\mathrm{ct}}$ increases. The decrease in $C_{\mathrm{dl}}$ and $Q$ values can be attributed to a decrease in local dielectric constant and/or an increase in the thickness of electrical double layer. Meanwhile the increase in $R_{\mathrm{ct}}$ indicates the increase in the extent of adsorption of inhibitor molecules and also the adsorbed RS molecules form a protective film on the mild steel surface which becomes a barrier to hinder the mass and charge transfer processes [6]. In Figure 9, only one time constant was observed and the phase angle increases with increasing concentration of RS. This signifies the decrease in surface inhomogeneity [38]. As a result the protection efficiency increases by increasing the concentration of RS. The obtained values of inhibition efficiency are in good agreement with those obtained from weight loss and potentiodynamic polarization measurements.

3.2.3. Chronoamperometric Measurements. The ability of RS to inhibit anodic processes of mild steel was investigated by the chronoamperometric measurements. The experiments were carried out by polarizing anodically the electrode potential at $-0.41 \mathrm{~V}$ (versus SCE) for $600 \mathrm{~s}$. The current density values obtained during the electrooxidation of mild steel were recorded in $1 \mathrm{M} \mathrm{HCl}$ in the absence and presence of different concentrations of RS and the chronoamperometric curves are depicted in Figure 10. By the addition of RS, the current density get reduced and the reduction in the current is more pronounced in $1 \mathrm{mM}$ solution compared to uninhibited solution. This confirms that the rate of mild steel dissolution decreases in the presence of RS in $1 \mathrm{M} \mathrm{HCl}$.

3.3. Mechanism of Inhibition. Based on the experimental results obtained, we could propose a probable mechanism for corrosion inhibition behavior of RS in $1 \mathrm{M} \mathrm{HCl}$. The polarization data suggested the mixed inhibition mechanism of RS.

In acidic media, RS might be protonated as follows;

$$
\mathrm{RS}+n \mathrm{H}^{+} \longrightarrow\left[\mathrm{RSH}_{n}\right]^{n+} \text {. }
$$

The cationic forms of RS may be adsorbed directly at the cathodic sites and hinder the hydrogen evolution reaction. In acid solutions, mild steel possesses positive charge at the corrosion potential. The chloride ions present in the solution get adsorbed on metal surface by creating an excess negative charge towards solution and it favors the adsorption of protonated inhibitor molecules on metal surface through electrostatic attraction $[39,40]$. Therefore the protonated RS molecules get adsorbed on mild steel surface by means of electrostatic interaction between chloride ions and inhibitor cations. Simultaneously, RS may also adsorb at anodic sites of metal surface via chemisorption mechanism by sharing electrons of $\mathrm{S}, \mathrm{N}$, and $\mathrm{O}$ atoms and also by donor acceptor interactions between $\pi$-electrons of methyl pyridine ring, benzimidazole ring, and vacant $\mathrm{d}$ orbital of iron $[3,41]$. By following the above mechanism, RS shows mixed inhibition behavior by inhibiting cathodic hydrogen evolution and anodic mild steel dissolution reactions.

Oguzie et al. reported that sulphur containing substances prefers chemisorption on metal surface in acidic media whereas nitrogen containing compounds tends to favor 
physisorption [42]. However, RS molecule is composed of both $\mathrm{N}$ and $\mathrm{S}$ atoms and hence it prefers physisorption accompanied by chemisorption which is also supported by thermodynamic calculations.

Even though RS shows mixed inhibition behavior via comprehensive adsorption in both $\mathrm{H}_{2} \mathrm{SO}_{4}$ and $\mathrm{HCl}$ solutions, the performance of inhibitor is not of equal importance in $1 \mathrm{M} \mathrm{HCl}$ compared to $0.5 \mathrm{M} \mathrm{H}_{2} \mathrm{SO}_{4}$. In the previous work it has been reported that RS shows $98 \%$ inhibition efficiency at $1 \mathrm{mM}$ concentration in $0.5 \mathrm{M} \mathrm{H}_{2} \mathrm{SO}_{4}$ but in the present work it shows nearly $90 \%$ efficiency in $1 \mathrm{M} \mathrm{HCl}$. This may be due to the availability of more sites on the metal surface in sulphuric acid solution because of lesser adsorption of sulfate ions on the mild steel surface [43] but RS is an effective inhibitor in $1 \mathrm{M} \mathrm{HCl}$ also. The effectiveness of RS is due to the presence of electron donating $\mathrm{S}$, two $\mathrm{O}$, and three $\mathrm{N}$ atoms as well as the $\pi$-electrons of methyl pyridine and benzimidazole rings.

\section{Conclusion}

The results reveal that RS is an efficient acid corrosion inhibitor for mild steel in $1 \mathrm{M} \mathrm{HCl}$. It acts as a mixed-type inhibitor by inhibiting both anodic and cathodic reactions. The corrosion rate decreases with inhibitor concentration and increases with the temperature. The adsorption of RS follows the Langmuir adsorption isotherm model and the adsorption is spontaneous and exothermic process. The kinetic and thermodynamic parameters of corrosion and adsorption processes are determined. The results obtained from weight loss measurements are comparable with those obtained from electrochemical measurements.

\section{Acknowledgments}

The authors are grateful to the authorities of the Department of Chemistry, Kuvempu University, Karnataka, India, for providing lab facilities. They also thank the Department of Science and Technology, New Delhi, Government. of India (DST: Project Sanction no. 100/IFD/1924/2008-2009 dated July 2,2008 ) for providing instrumental facilities.

\section{References}

[1] A. K. Singh and M. A. Quraishi, "Effect of Cefazolin on the corrosion of mild steel in $\mathrm{HCl}$ solution," Corrosion Science, vol. 52, no. 1, pp. 152-160, 2010.

[2] A. Doner, R. Solmaz, M. Ozcan, and G. Kardas, "Experimental and theoretical studies of thiazoles as corrosion inhibitors for mild steel in sulphuric acid solution," Corrosion Science, vol. 53, no. 9, pp. 2902-2913, 2011.

[3] Z. Tao, S. Zhang, W. Li, and B. Hou, "Adsorption and inhibitory mechanism of $1 \mathrm{H}-1,2$, 4-triazol-1-yl-methyl-2-(4chlorophenoxy) acetate on corrosion of mild steel in acidic solution," Industrial and Engineering Chemistry Research, vol. 50, no. 10, pp. 6082-6088, 2011.

[4] M. Lebrini, F. Robert, H. Vezin, and C. Roos, "Electrochemical and quantum chemical studies of some indole derivatives as corrosion inhibitors for C38 steel in molar hydrochloric acid," Corrosion Science, vol. 52, no. 10, pp. 3367-3376, 2010.
[5] F. Bentiss, M. Lebrini, M. Traisnel, and M. Lagrenée, "Synergistic effect of iodide ions on inhibitive performance of 2,5-bis(4-methoxyphenyl)-1,3,4-thiadiazole during corrosion of mild steel in $0.5 \mathrm{M}$ sulfuric acid solution," Journal of Applied Electrochemistry, vol. 39, no. 8, pp. 1399-1407, 2009.

[6] W. Chen, H. Q. Luo, and N. B. Li, "Inhibition effects of 2, 5dimercapto-1, 3, 4-thiadiazole on the corrosion of mild steel in sulphuric acid solution," Corrosion Science, vol. 53, no. 10, pp. 3356-3365, 2011.

[7] K. M. Govindaraju, D. Gopi, and L. Kavitha, "Inhibiting effects of 4-amino-antipyrine based schiff base derivatives on the corrosion of mild steel in hydrochloric acid," Journal of Applied Electrochemistry, vol. 39, no. 12, pp. 2345-2352, 2009.

[8] X. Wang, H. Yang, and F. Wang, "An investigation of benzimidazole derivative as corrosion inhibitor for mild steel in different concentration HCl solutions," Corrosion Science, vol. 53, no. 1, pp. 113-121, 2011.

[9] P. Lowmunkhong, D. Ungthararak, and P. Sutthivaiyakit, "Tryptamine as a corrosion inhibitor of mild steel in hydrochloric acid solution," Corrosion Science, vol. 52, no. 1, pp. 30-36, 2010.

[10] A. Singh, E. E. Ebenso, and M. A. Quraishi, "Corrosion inhibition of carbon steel in $\mathrm{HCl}$ solution by some plant extracts," International Journal of Corrosion, vol. 2012, Article ID 897430, 20 pages, 2012.

[11] D. Ben Hmamou, R. Salghi, A. Zarrouk et al., "Corrosion inhibition of steel in $1 \mathrm{M}$ hydrochloric acid medium by chamomile essential oils," International Journal of Electrochemical Science, vol. 7, pp. 2361-2373, 2012.

[12] N. O. Eddy, E. E. Ebenso, and U. J. Ibok, "Adsorption, synergistic inhibitive effect and quantum chemical studies of ampicillin (AMP) and halides for the corrosion of mild steel in $\mathrm{H} 2 \mathrm{SO} 4$," Journal of Applied Electrochemistry, vol. 40, no. 2, pp. 445-456, 2010.

[13] I. B. Obot, N. O. Obi-Egbedi, and S. A. Umoren, "Antifungal drugs as corrosion inhibitors for aluminium in $0.1 \mathrm{M} \mathrm{HCl}$," Corrosion Science, vol. 51, no. 8, pp. 1868-1875, 2009.

[14] M. M. El-Naggar, "Corrosion inhibition of mild steel in acidic medium by some sulfa drugs compounds," Corrosion Science, vol. 49, no. 5, pp. 2226-2236, 2007.

[15] M. Abdallah, "Rhodanine azosulpha drugs as corrosion inhibitors for corrosion of 304 stainless steel in hydrochloric acid solution," Corrosion Science, vol. 44, no. 4, pp. 717-728, 2002.

[16] R. A. Prabhu, A. V. Shanbhag, and T. V. Venkatesha, "Influence of tramadol [2-[(dimethylamino)methyl]-1-(3-methoxyphenyl) cyclohexanol hydrate] on corrosion inhibition of mild steel in acidic media," Journal of Applied Electrochemistry, vol. 37, no. 4, pp. 491-497, 2007.

[17] S. E. Nataraja, T. V. Venkatesha, and H. C. Tandon, "Computational and experimental evaluation of the acid corrosion inhibition of steel by tacrine," Corrosion Science, vol. 60, pp. 214223, 2012.

[18] M. K. Pavithra, T. V. Venkatesha, M. K. Punith Kumar, and H. C. Tandon, "Inhibition of mild steel corrosion by Rabeprazole sulfide," Corrosion Science, vol. 60, pp. 104-111, 2012.

[19] A. Popova, E. Sokolova, S. Raicheca, and M. Christov, "AC and DC study of the temperature effect on mild steel corrosion in acid media in the presence of benzimidazole derivatives," Corrosion Science, vol. 45, no. 1, pp. 33-58, 2003.

[20] M. Liang, H. Zhou, Q. Huang, S. Hu, and W. Li, "Synergistic effect of polyethylene glycol 600 and polysorbate 20 on corrosion inhibition of zinc anode in alkaline batteries," Journal of Applied Electrochemistry, vol. 41, no. 8, pp. 991-997, 2011. 
[21] M. A. Quraishi, M. Z. A. Rafiquee, S. Khan, and N. Saxena, "Corrosion inhibition of aluminium in acid solutions by some imidazoline derivatives," Journal of Applied Electrochemistry, vol. 37, no. 10, pp. 1153-1162, 2007.

[22] D. Gopi, K. M. Govindaraju, and L. Kavitha, "Investigation of triazole derived Schiff bases as corrosion inhibitors for mild steel in hydrochloric acid medium," Journal of Applied Electrochemistry, vol. 40, no. 7, pp. 1349-1356, 2010.

[23] R. Laamari, J. Benzakour, F. Berrekhis, A. Abouelfida, A. Derja, and D. Villemin, "Corrosion inhibition of carbon steel in hydrochloric acid $0.5 \mathrm{M}$ by hexa methylene diamine tetramethyl-phosphonic acid," Arabian Journal of Chemistry, vol. 4, no. 3, pp. 271-277, 2011.

[24] E. A. Noor, "Temperature effects on the corrosion inhibition of mild steel in acidic Solutions by aqueos extract of Fenugreek leaves," International Journal of Electrochemical Science, vol. 2, pp. 996-1017, 2007.

[25] A. Ostovari, S. M. Hoseinieh, M. Peikari, S. R. Shadizadeh, and S. J. Hashemi, "Corrosion inhibition of mild steel in 1 $\mathrm{M} \mathrm{HCl}$ solution by henna extract: a comparative study of the inhibition by henna and its constituents (Lawsone, Gallic acid, $\alpha$-d-Glucose and Tannic acid)," Corrosion Science, vol. 51, no. 9, pp. 1935-1949, 2009.

[26] E. A. Noor, "Potential of aqueous extract of Hibiscus sabdariffa leaves for inhibiting the corrosion of aluminum in alkaline solutions," Journal of Applied Electrochemistry, vol. 39, no. 9, pp. 1465-1475, 2009.

[27] A. M. Badiea and K. N. Mohana, "Effect of temperature and fluid velocity on corrosion mechanism of low carbon steel in presence of 2-hydrazino-4,7-dimethylbenzothiazole in industrial water medium," Corrosion Science, vol. 51, no. 9, pp. 2231-2241, 2009.

[28] M. G. Hosseini, H. Khalilpur, S. Ershad, and L. Saghatforoush, "Protection of mild steel corrosion with new thia-derivative Salens in $0.5 \mathrm{M} \mathrm{H}_{2} \mathrm{SO}_{4}$," Journal of Applied Electrochemistry, vol. 40, pp. 215-223, 2009.

[29] G. Mu, X. Li, and G. Liu, "Synergistic inhibition between tween 60 and $\mathrm{NaCl}$ on the corrosion of cold rolled steel in $0.5 \mathrm{M}$ sulfuric acid," Corrosion Science, vol. 47, no. 8, pp. 1932-1952, 2005.

[30] A. S. Fouda, F. E. Heakal, and M. S. Radwan, "Role of some thiadiazole derivatives as inhibitors for the corrosion of C-steel in $1 \mathrm{M} \mathrm{H}_{2} \mathrm{SO}_{4}$," Journal of Applied Electrochemistry, vol. 39, no. 3, pp. 391-402, 2009.

[31] A. R. S. Priya, V. S. Muralidharam, and A. Subramania, "Development of novel acidizing inhibitors for carbon steel corrosion in $15 \%$ boiling hydrochloric acid," Corrosion, vol. 64, no. 6, pp. 541-552, 2008.

[32] A. Y. Musa, A. A. Amir, H. Kadhum et al., "On the inhibition of mild steel corrosion by 4-amino-5-phenyl-4H-1, 2, 4-trizole-3thiol," Corrosion Science, vol. 52, no. 2, pp. 526-533, 2010.

[33] N. O. Obi-Egbedi and I. B. Obot, "Inhibitive properties, thermodynamic and quantum chemical studies of alloxazine on mild steel corrosion in $\mathrm{H}_{2} \mathrm{SO}_{4}$," Corrosion Science, vol. 53, no. 1, pp. 263-275, 2011.

[34] W. Li, Q. He, S. Zhang, C. Pei, and B. Hou, "Some new triazole derivatives as inhibitors for mild steel corrosion in acidic medium," Journal of Applied Electrochemistry, vol. 38, no. 3, pp. 289-295, 2008.

[35] X. Li, S. Deng, H. Fui, and G. Mu, "Synergistic inhibition effect of rare earth cerium(IV) ion and sodium oleate on the corrosion of cold rolled steel in phosphoric acid solution," Corrosion Science, vol. 52, no. 4, pp. 1167-1178, 2010.

[36] M. Lebrini, F. Robert, and C. Roos, "Alkaloids extract from Palicourea guianensis plant as corrosion inhibitor for C38 steel in $1 \mathrm{M}$ hydrochloric acid medium," International Journal of Electrochemical Science, vol. 6, no. 3, pp. 847-859, 2011.

[37] Z. Wu, Z. Fang, L. Qiu et al., "Synergistic inhibition between the gemini surfactant and bromide ion for steel corrosion in sulphuric acid," Journal of Applied Electrochemistry, vol. 39, no. 6, pp. 779-784, 2009.

[38] S. S. A. Rehim, O. A. Hazzazi, M. A. Amin, and K. F. Khaled, "On the corrosion inhibition of low carbon steel in concentrated sulphuric acid solutions. Part I: chemical and electrochemical (AC and DC) studies," Corrosion Science, vol. 50, no. 8, pp. 2258-2271, 2008.

[39] M. K. Pavithra, T. V. Venkatesha, M. K. Punith Kumar, and B. S. Shylesha, "Acalypha torta leaf extract as green corrosion inhibitor for mild steel in hydrochloric acid solution," Industrial and Engineering Chemistry Research, vol. 52, no. 2, pp. 722-728, 2013.

[40] M. K. Pavithra, T. V. Venkatesha, K. Vathsala, and K. O. Nayana, "Synergistic effect of halide ions on improving corrosion inhibition behaviour of benzisothiozole-3-piperizine hydrochloride on mild steel in $0.5 \mathrm{M} \mathrm{H}_{2} \mathrm{SO}_{4}$ medium," Corrosion Science, vol. 52, no. 11, pp. 3811-3819, 2010.

[41] X. Li, S. Deng, H. Fui, and G. Mu, "Inhibition effect of 6-benzylaminopurine on the corrosion of cold rolled steel in $\mathrm{H}_{2} \mathrm{SO}_{4}$ solution," Corrosion Science, vol. 51, no. 3, pp. 620-634, 2009.

[42] E. E. Oguzie, Y. Li, and F. H. Wang, "Corrosion inhibition and adsorption behavior of methionine on mild steel in sulfuric acid and synergistic effect of iodide ion," Journal of Colloid and Interface Science, vol. 310, no. 1, pp. 90-98, 2007.

[43] I. Ahamad and M. A. Quraishi, "Bis (benzimidazol-2-yl) disulphide: an efficient water soluble inhibitor for corrosion of mild steel in acid media," Corrosion Science, vol. 51, no. 9, pp. 20062013, 2009. 

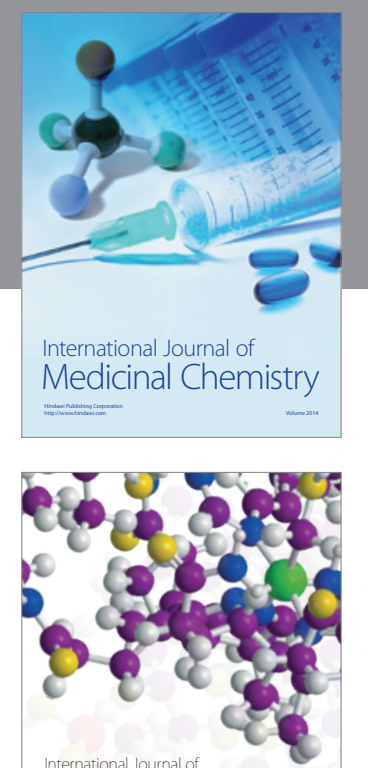

\section{Carbohydrate} Chemistry

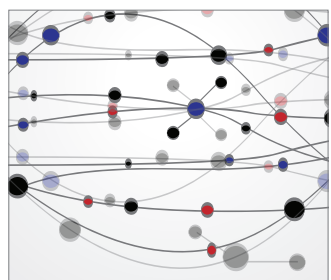

The Scientific World Journal
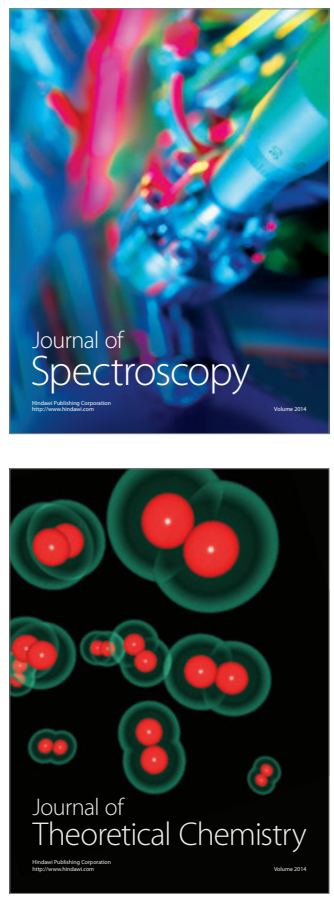
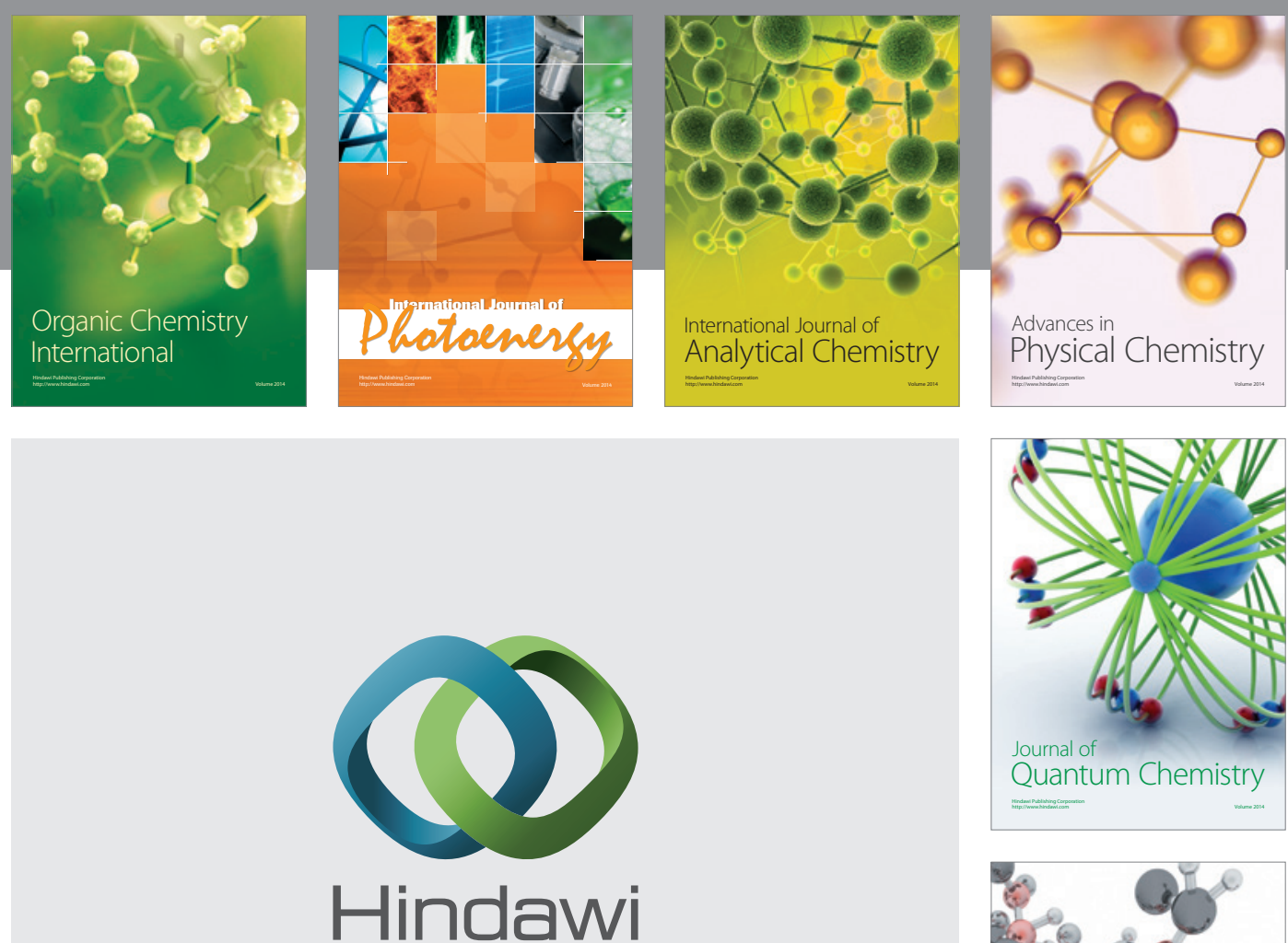

Submit your manuscripts at

http://www.hindawi.com

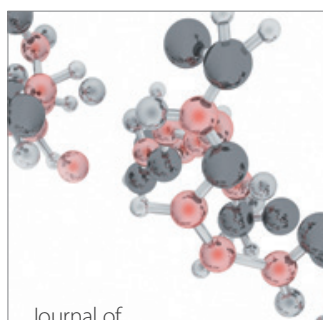

Analytical Methods

in Chemistry

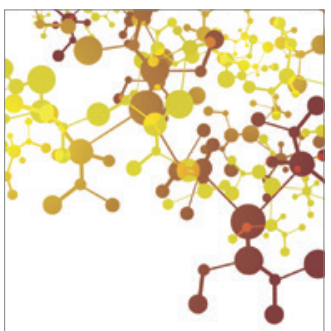

Journal of

Applied Chemistry

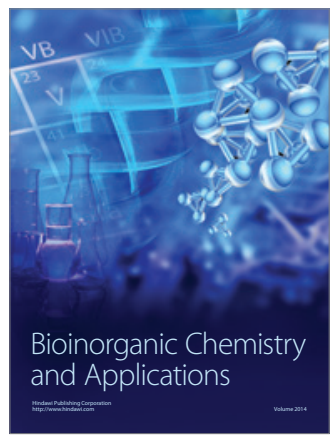

Inorganic Chemistry
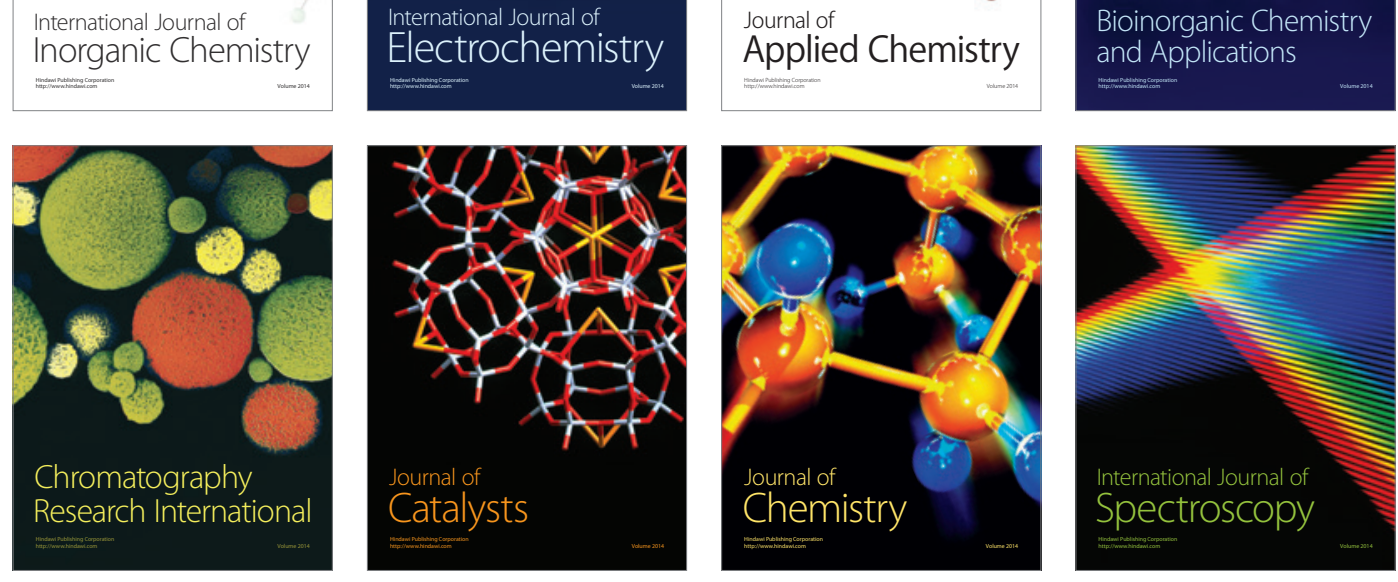